\title{
PROMOTION OF CATALYTIC PROPERTIES OF VANILLIN LOADED MCM-41 BY Cu(I) AND Cu(II) FOR ENHANCED REMOVAL OF QUINOLINE CONTAMINANTS
}

\author{
MINA KAMANI ${ }^{a}$, REZA FAZAELI ${ }^{a^{*}}$, MEHDI ARJMAND ${ }^{b}$ AND MOHAMMAD HOSSEIN GHORBANI ${ }^{a}$ \\ ${ }^{a}$ Department of Chemistry, South Tehran Branch, Islamic Azad University, Tehran, 11365-4435, Iran. \\ ${ }^{b}$ Department of Chemical Engineering, South Tehran Branch, Islamic Azad University, Tehran, 11365-4435, Iran.
}

\begin{abstract}
In the present study, to enhance removal of quinoline contaminants using natural active component, vanillin was loaded onto the MCM-41 (Mobile Component Material) nanoparticles in a simple way. The product was divided into two parts, which were improved by Copper(I) and Copper(II) salts. Promoted synthetic nanocatalysts (Cu(I)/Van./MCM-41, and $\mathrm{Cu}(\mathrm{II}) / \mathrm{Van} . / \mathrm{MCM}-41)$ were characterized using X-Ray Diffraction (XRD), Field Emission Scanning Electron Microscopy (FESEM), Energy-Dispersive X-Ray Spectroscopy (EDS), Mapping, Fourier-Transform Infrared Spectroscopy (FTIR), and BET/BJH (Brunauer-Emmett-Teller (BET) and Barret-Joyner-Halenda (BJH)) techniques. To reach optimal conditions, experimental design was performed using Response Surface Methodology (RSM). The experiments were done with the aid of nanocomposites, in presence of ultraviolet radiation without any auxiliary oxidants. Degradation percentages were measured by an Ultraviolet (UV) spectrophotometer. The products were identified using Gas Chromatography-Mass (GC-Mass) technique, and some mechanisms for quinoline removal were proposed. The results indicated that $\mathrm{Cu}$ (I) showed better performance in enhanced removal of quinoline than $\mathrm{Cu}(\mathrm{II})$.
\end{abstract}

Keywords: Catalytic Properties, Quinoline, Response Surface Methodology, Vanillin/MCM-41.

\section{INTRODUCTION}

Sulfur and nitrogen contents in diesel and gasoline fuels are determined according to international regulations [1]. Ultra-Low Sulfur Diesel (ULSD below 10 ppmw) fuel is desirable (under EURO IV standards) [2]. The amount of nitrogen is also important due to the need for nitrogen to inhibit catalytic activator during HDS (Hydrodesulfurization) reaction. Moreover, controlling of nitrogen and sulfur is also important during crude oil refining [3]. Firstly, as nitrogen compounds can poison active acidic sites of catalysts $[4,5]$, and secondly, produced nitrogen oxide and sulfur [6,7] cause greenhouse effect, acid rain, air pollution, climate change, respiratory diseases and so on [8]. These results have left serious problems for the planet.

Therefore, using modern and efficient methods to maintain health of living organisms as well as maintaining a healthy environment is very important. There are different methods for denitrogenation and desulfurization of diesel fuels each of which has, in turn, caused these chemicals to become less harmful [9-12]. Among these methods, advanced oxidation processes, including ultraviolet/oxidation process and heterogeneous photocatalysis have received much attention [13, 14], because of their low cost, non-toxicity and noncorrosive, easy recovery and reusability, and environmentally benign[15]. In addition, the use of advanced catalysts causing catalytic oxidation or pollutant degradation is popular [16]. These catalysts usually contain a metal or metal oxide (as the active component), which is mounted on an alumina or silica base [17-22] and can be promoted with promoter components.

Regarding production of these catalysts, metallic nanoparticles have received much attention due to their shape, size, size-dependent properties [18, 19], and physical and chemical properties of each metal [20]. Copper and its family also possess a wide range of properties such as low cost, electron correlation effects, superconductivity, spin dynamics, surface size, and property [21].

MCM-41 with a diameter of $2-10 \mathrm{~nm}$ is the most well-known one-dimensional silica material with a hexagonal arrangement [21, 22]. Because of their nature, these pores can become functional and participate in reactions [23]. The MCM41 is favored by many scientists in the fields of nanotechnology, catalysis [24, 25], and environmental filtration because of its large surface area, homogeneous and accessible porosity, good thermal stability, adsorption [26], and also the capability of drug delivery [27].

Ghorbani-Choghamarani, et al. (2015) synthesized the Pd (II)-MCM-41 complex by functionalizing MCM-41. This novel complex was used as an effective catalyst for formation of C-C, C-O, and C-N bonds. Properties such as high thermal and chemical stability, air resistance, ease of preparation, and easy separation from the reaction made this complex an ideal homogeneous green catalyst [21].

Wei, et al. (2016) synthesized MCM-41@ $\mathrm{mTiO}_{2}$. They used it to decompose 2-sec-butyl-4,6-dinitrophenol under UV and visible lights. Then, they compared the results with commercial anatase $\mathrm{TiO}_{2}$ and Degussa P25. Their synthetic composite was found to be more successful in degradation, and it can be used as a detergent for harmful organic pollutants in wastewater [28].

In another study, Sadeghi, et al. (2017) synthesized Pb-MCM-41/ZnNiO composite. Their goal was to produce a destructive adsorbent for Chloroethyl Phenyl Sulfide (CEPS) contamination for the first time and their synthesized adsorbent was able to decompose CEPS by more than $90 \%$, due to potential and high capacity of the nanocomposite [9].

Khanmoradi, et al. (2017) synthesized Cu(II)/Van. /MCM-41 nanocatalyst, which was used as a recyclable catalyst. They investigated efficiency of synthetic catalysts for sulfide synthesis, sulfide conversion to sulfoxides, and synthesis of 5 -substituted $1 \mathrm{H}$-tetrazoles. The method used for synthesis of this nanocatalyst is illustrated in Figure 2 [29].

Lin, et al. (2018) to deepen oxidation-adsorption desulfurization process for aromatic sulfur compounds, synthesized three kinds of Ti-HMS zeolites. One of them, Ti-HMS-12, showed $99.9 \%$ desulfurization using cyclohexanone peroxide (as an oxidant) and without solvents. Their synthetic catalyst was able to recycle up to 5 runs [30].

Bhadra, et al. (2019) performed possible nitrogen desulfurization of fuels using a $\mathrm{TiO}_{2}$-containing carbon catalyst. They prepared it through pyrolysis of a MOFcomposite [ZIF-8 (30) @H2N-MIL-125]. They showed that MDC-C was very effective in oxidative nitrogen degradation. Among its properties, one can point to the capability of recycling up to 4 runs. They showed that increasing electrophilicity of oxygen atoms on the substrates plays an essential role in oxidation, and they suggested conduction of further studies to support this hypothesis [31]

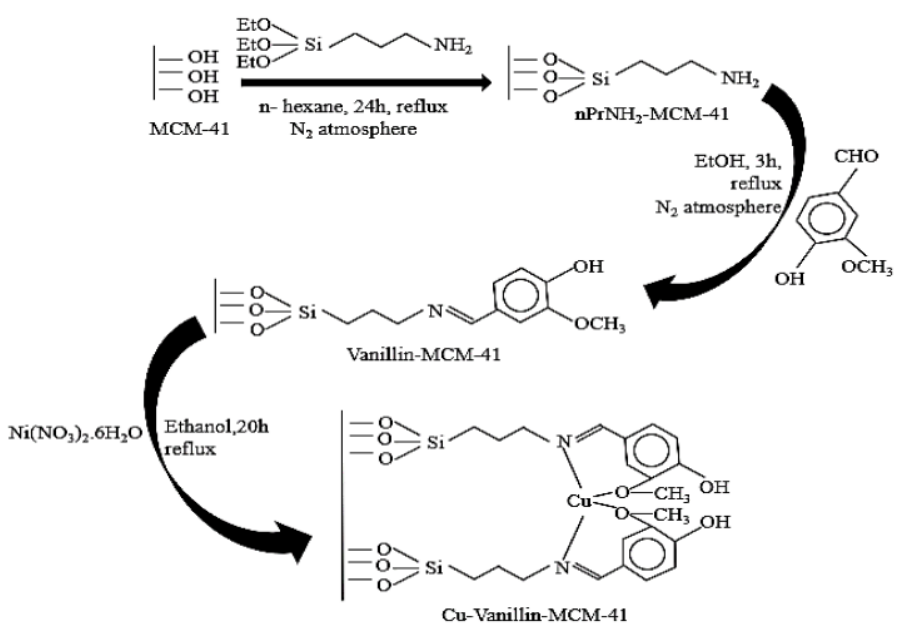

Figure 2: Synthesis of Cu(II)-vanillin-MCM-41[29]. 
In another study, in 2019, Chen et al. synthesized Ag catalysts supported on carbon nanotubes. They used two reducing agents, denoted as GL and DMSO samples. Using synthetic compounds, they increased catalytic activity of formaldehyde oxidation. One of the samples containing $\mathrm{Ag}$ content less than 10 times compared to the others showed $90 \% \mathrm{HCHO}$ conversion at $150{ }^{\circ} \mathrm{C}[32]$.

In this research, to remove quinoline (one of main nitrogen compounds), 2 nanocatalysts $\mathrm{Cu}(\mathrm{I}) / \mathrm{Van} . / \mathrm{MCM}-41$ \& $\mathrm{Cu}(\mathrm{II}) / \mathrm{Van} . / \mathrm{MCM}-41$ were synthesized more easily than previous works [29] and were characterized by XRD, FESEM, EDS, Mapping, FTIR, and BET/BJH techniques. Removal efficiencies were determined by statistical methods.

\section{EXPERIMENTS}

\subsection{Materials}

Sodium Hydroxide $(\mathrm{NaOH})$, Cetyltrimethylammonium Bromide (CTAB), Tetraethyl Orthosilicate (TEOS), Ethanol $\left(\mathrm{C}_{2} \mathrm{H}_{5} \mathrm{OH}\right)$, (3-Aminopropyl) Triethoxysilane (APTES), Vanillin powder, Hydrochloric Acid 37\%, Copper(II) Chloride $\left(\mathrm{CuCl}_{2}\right)$, Copper(I) Acetate $\left(\mathrm{CuCH}_{3} \mathrm{COO}\right)$, and Quinoline were purchased from Merck Company (Germany). All of the chemicals were used without further purification.

\subsection{Design of Experiments (DOE)}

The Design Expert Software (DX-Version 11.0.3) and RSM procedure were used for test designing. Two different states of copper were analyzed. In the first case, $\mathrm{Cu}$ (I) and in the second case, $\mathrm{Cu}$ (II) was added to MCM-41/vanillin composite. Due to the fact that, MCM-41 has been active with vanillin in both cases and then copper salts have been added, thus these interactions are expected to be stable. If the data is stable and test conditions have a normal process, then composite test design or the CCD technique can be used. This method is among standards and normal methods with suitable conditions for these materials.

\subsubsection{Effect of $\mathbf{p H}$, Pollutant Concentration, and Composite Mass on} Pollutant Treatment

To design the test, the effects of hidden variables on pollutant treatment were determined using standard works, to obtain selected intervals to the software. After preliminary tests, confidence interval was determined for each one of the variables and was also introduced as confidence interval of each variable to the software.

$\mathrm{pH}$ level ranged from 3 to 11 , pollutant concentration was between $2-32$ $\mathrm{mg} / \mathrm{L}$, and mass of the composite was between 0.004-0.12 g. Accordingly, the test version was prepared after entering declared numbers into test design software.

\subsubsection{Test Design Table}

After the test designing by the software, the experiments were performed according to Table 1 as follows:

Table 1. Designing of the experiments to investigate the effects of $\mathrm{Cu}$ (I) and $\mathrm{Cu}(\mathrm{II})$

\begin{tabular}{|c|c|c|c|c|c|}
\hline \multirow{2}{*}{ Run } & \multirow{2}{*}{ A: Composite (g) } & \multirow{2}{*}{ B: Pollutant Conc. (mg/L) } & \multirow{2}{*}{ C: $\mathbf{p H}$} & \multicolumn{2}{|c|}{ Efficiency } \\
\hline & & & & $\mathrm{Cu}(\mathrm{I})$ & $\mathrm{Cu}(\mathrm{II})$ \\
\hline 1 & 0.12 & 32 & 11 & -55.00 & -10.05 \\
\hline 2 & 0.03 & 17 & 7 & -25.11 & -9.95 \\
\hline 3 & 0.004 & 2 & 11 & -53.33 & -68.00 \\
\hline 4 & 0.06 & 9 & 7 & -60.60 & -18.49 \\
\hline 5 & 0.06 & 17 & 5 & -48.50 & -13.63 \\
\hline 6 & 0.004 & 32 & 11 & -3.70 & -7.91 \\
\hline 7 & 0.06 & 17 & 7 & -39.85 & -13.50 \\
\hline 8 & 0.06 & 17 & 7 & -54.00 & -7.32 \\
\hline 9 & 0.004 & 2 & 3 & -35.76 & -46.05 \\
\hline 10 & 0.06 & 25 & 7 & -37.40 & -7.34 \\
\hline 11 & 0.06 & 17 & 7 & -53.20 & -12.50 \\
\hline 12 & 0.12 & 32 & 3 & -73.45 & 11.55 \\
\hline 13 & 0.12 & 2 & 3 & -257.58 & -71.71 \\
\hline 14 & 0.06 & 17 & 7 & -61.35 & -8.12 \\
\hline 15 & 0.004 & 32 & 3 & 70.00 & 14.92 \\
\hline 16 & 0.06 & 17 & 9 & -43.50 & -13.55 \\
\hline 17 & 0.06 & 17 & 7 & -63.01 & -15.45 \\
\hline 18 & 0.12 & 2 & 11 & -855.80 & -123.20 \\
\hline 19 & 0.06 & 17 & 7 & -61.65 & -13.73 \\
\hline 20 & 0.09 & 17 & 7 & -65.87 & -14.76 \\
\hline
\end{tabular}

\subsection{Preparation of Composite}

$1^{\text {st }}$ step: MCM-41: First, 960ml Deionized Water $+\mathrm{NaOH} 2 \mathrm{M}+\mathrm{CTAB}+$ Stirring it for $30 \mathrm{~min}$ at $80^{\circ} \mathrm{C}+10 \mathrm{ml}$ TEOS + Refluxing it for $2 \mathrm{~h}$ at $80^{\circ} \mathrm{C}+$ Cooling it Down + Filtering $\&$ Rinsing it + Calcining it,

$2^{\text {nd }}$ Step: MCM-41 + Linker: Then, $5 \mathrm{~g}$ from step1 $+100 \mathrm{ml}$ Ethanol Dissolving it + APTES Refluxing it for $10 \mathrm{~h}$ at $70^{\circ} \mathrm{C}$ Separating the sediment Rinsing it with Ethanol Drying it.,

$3^{\text {rd }}$ Step: Vanillin/MCM-41: Then, $5 \mathrm{~g}$ from step2 $+100 \mathrm{ml}$ Vanillin solution Refluxing it for 15h Rinsing the sediment with Ethanol Drying it.,

$4^{\text {th }}$ Step: $\mathbf{C u}(\mathrm{I}) / \mathrm{Van} . / \mathrm{MCM}-41$ \& $\mathrm{Cu}(\mathrm{II}) / \mathrm{Van} . / \mathrm{MCM}-41$ : Product of step3 + $\mathrm{Cu}(\mathrm{I}) / \mathrm{Cu}$ (II) solution (in Ethanol) Stirring it for 1day (door closing) Stirring it for $1 \mathrm{~h}$ at $40^{\circ} \mathrm{C}$ Isolating Rinsing the sediment with Ethanol Drying it at $40^{\circ} \mathrm{C}$.

\subsection{Removal Studies}

\section{UV Spectrophotometer}

The Duplex UV spectrophotometer (PG Instruments, T80+) was used to measure solution absorbance using a $1 \mathrm{~cm}$ quartz cell.
The quinoline with a maximum absorption wavelength of $313 \mathrm{~nm}$ was selected as a pollutant to assess adsorption and optical activity of the nanocomposite. For this purpose, $0.008 \mathrm{~g}$ of different composites was added to $20 \mathrm{~mL}$ of quinoline solution at a concentration of $2 \mathrm{mg} / \mathrm{L}$. To investigate photocatalytic process, UV light was used in an optical reactor equipped with a mercury lamp, Philips $9 \mathrm{~W}$ (UV-C).

$\mathrm{pH}$ was adjusted to desired level using $1 \mathrm{M} \mathrm{NaOH}$ and $\mathrm{HCl}$. Percentage removal of quinoline $(\% \mathrm{R})$ was defined as a function of time with respect to the Eq. 1 [33]:

Efficiency $\%=\frac{\mathrm{A}_{0}-\mathrm{A}}{\mathrm{A}_{0}} \times 100$

Where, $\mathrm{A}_{0}$ and $\mathrm{A}$ are quinoline absorption at $\mathrm{t}=0$ and $\mathrm{t}=\mathrm{t}$, respectively. The effect of concentration of nanocomposites on quinoline removal was investigated by $20 \mathrm{~mL}$ of quinoline solution with an initial concentration of $2 \mathrm{mg} / \mathrm{L}$ and $\mathrm{pH}=7$ for $40 \mathrm{~min}$ at room temperature. Different amounts of synthetic nanocomposites, namely $\mathrm{Cu}(\mathrm{I}) / \mathrm{Vanillin} / \mathrm{MCM}-41$ and $\mathrm{Cu}(\mathrm{II}) /$ Vanillin/MCM-41 (0.004, 0.03 , $0.06,0.009$, and $0.12 \mathrm{gr}$ ) were used in order to remove the quinoline. In addition, the effects of $\mathrm{pH}$ values $(3,7$, and 11) and initial concentration of quinoline (2, 17 , and $32 \mathrm{mg} / \mathrm{L}$ ) on quinoline removal by MCM-41 and two composites were similar to those of changing content of the nanocomposites. 


\section{Results and Discussion}

\subsection{Oxidation Process}

According to the GC-MASS results, chromatograms of test No. 4 for $\mathrm{Cu}$ (I)/Vanillin/MCM-41 and.
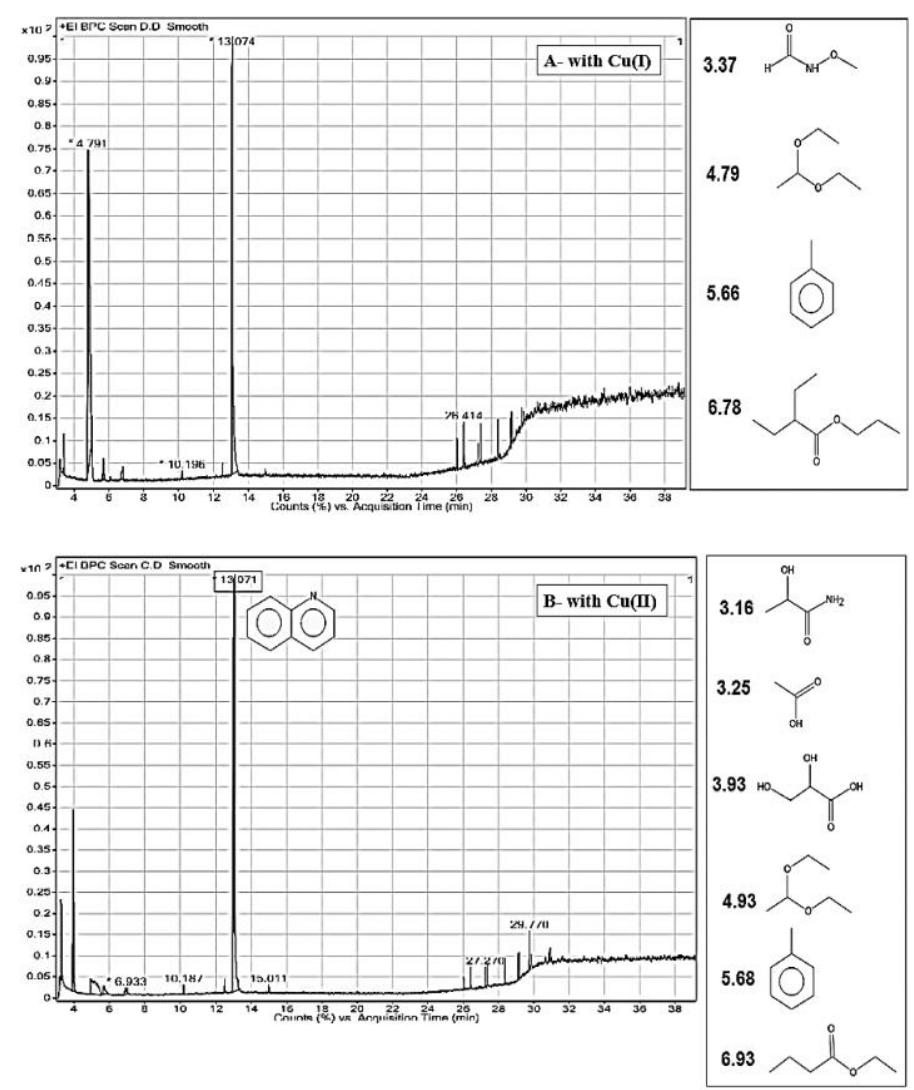

Figure 3. Chromatograms for test No.4, (A: Composite (g):0.06, B: Pollutant Conc. (mg/L):9, C: $\mathrm{pH}: 7$, Efficiencies for $\mathrm{Cu}(\mathrm{I}):-60.60 \%$, and $\mathrm{Cu}(\mathrm{II}):-18.49 \%)$.

$\mathrm{Cu}(\mathrm{II}) /$ Vanillin/MCM-41 composites are shown in Figure 3 (a) and (b), respectively. The compounds obtained through decomposition of this reaction are also presented in this figure.

It seems that, higher removal of quinoline occurred with $\mathrm{Cu}$ (I) than $\mathrm{Cu}$ (II), which can be explained by intensity of the quinoline peaks relative to noise of the device.

Peak 4.79 related to silane compounds indicates a high leakage of silane compounds and MCM-41 catalyst reactivity in this test.

Proposed mechanisms for produced compounds are illustrated in Figure 4((a), (b), (c), (d), (e), and (f))[34].

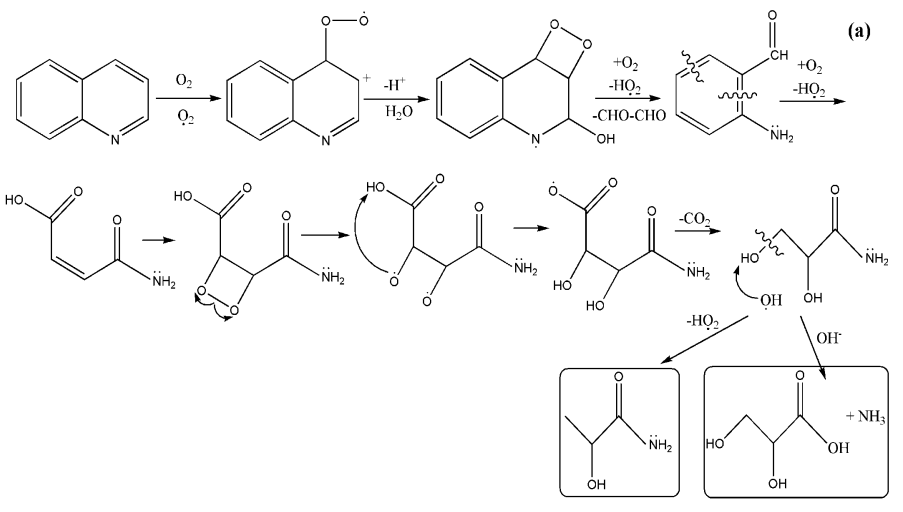

(b)

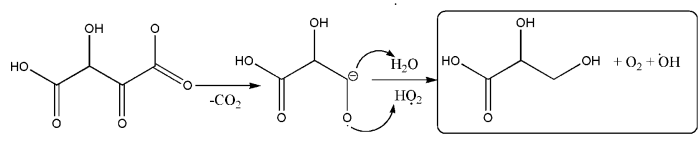

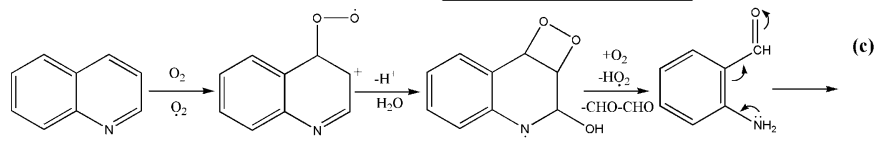

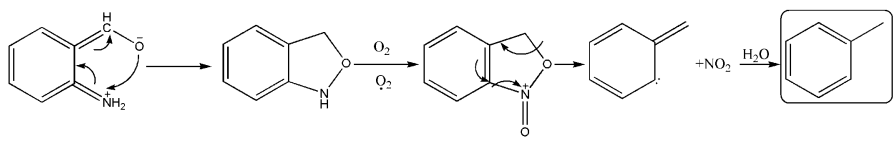
$\underset{N}{\stackrel{\mathrm{O}_{2}}{\longrightarrow}}$ (c)

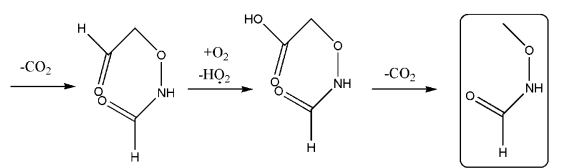
(e) (n) (n)

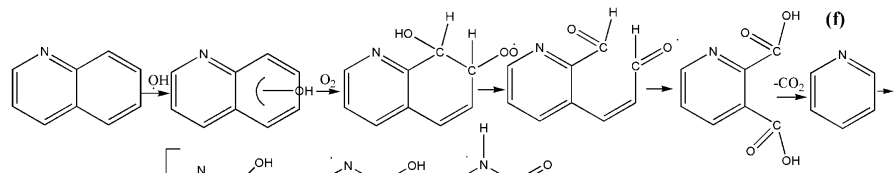

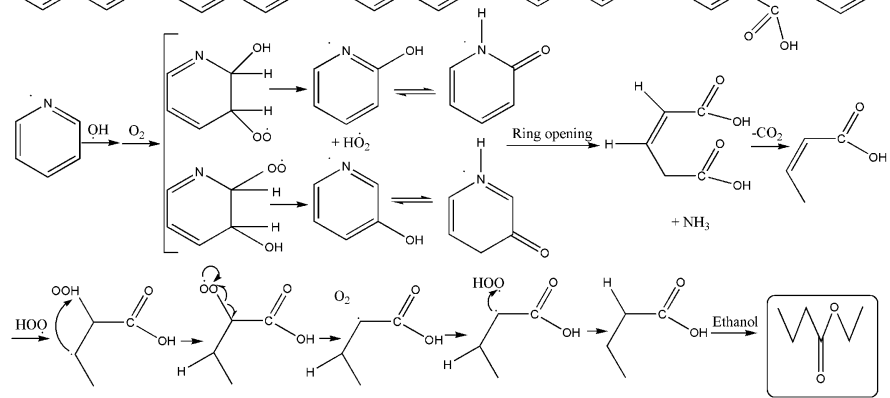

Figure 4. Proposed mechanisms for quinoline removal, related to the: a)3.16 $\& 3.93$, b) 3.93 , c)5.66 \& 5.68, d)3.27, e) $4.79 \& 4.93$, and f) 6.93 peaks[34]. 
Table 2 shows the ratio of residual quinoline concentration to internal standard. The ratio of 70 for $\mathrm{Cu}$ (II) corresponds to $18 \%$ removal efficiency. The smaller the ratio, the greater the removal efficiency.

Table 2. Results obtained from comparison between 2 tests.

\begin{tabular}{|c|c|c|c|c|c|}
\hline Test & Efficiency \% & Composite (g) & $\begin{array}{c}\text { Area 1 } \\
\text { (Quinolone 13.07) }\end{array}$ & $\begin{array}{c}\text { Area 2 } \\
\text { (IS 26.43) }\end{array}$ & $\begin{array}{c}\text { Ratio } \\
\mathbf{A 1 / A 2}\end{array}$ \\
\hline 4-Cu(I) & -60.60 & 0.06 & 164177 & 3542 & 46.35 \\
\hline 4-Cu(II) & -18.49 & 0.06 & 446313 & 6362 & 70.15 \\
\hline
\end{tabular}

\subsection{Statistical Analysis}

As shown in Table 1, the largest amount of pollutant treatment in both cases belonged to test No. 15 (which is equal to 70 and $14.92 \%$ for $\mathrm{Cu}(\mathrm{I})$ and $\mathrm{Cu}(\mathrm{II})$, respectively) compared to test No.6, which is the same for all variables except $\mathrm{pH}$. It can be concluded that, with alkalization of pollutant treatment environment, performance of the materials will be negatively influenced. Not only no removal occurs, but also level of pollutants will increase in the environment due to oxidation of the materials and development of adverse conditions. By studying test No. 1 that has the same conditions with test No. 6 except for composite variable, it can also be stated that, the increase in oxidation and contamination in solutions is likely to happen because they also increase amount of pollutant composite in the environment. $\mathrm{Cu}$ (I) has about 6-time positive effect compared to $\mathrm{Cu}$ (II) in pollutant treatment.

As presented in Tables 3 and 4, validity of the test in RSM model was less than 0.05 (0.0001), showing a significant difference between the effect of variable on pollutant treatment. Therefore, it can be concluded that, $\mathrm{pH}$, pollutant concentration, and amount of composite have significant effects on pollutant treatment.

Table 3. Results obtained from ANOVA analysis regarding pollutant removal with $\mathrm{Cu}$ (I).

\begin{tabular}{|c|c|c|c|c|c|c|}
\hline \multicolumn{7}{|c|}{ ANOVA Response Surface Methodology Quadratic Model } \\
\hline Source & Sum of Squares & df & Mean Square & F-value & p-value & \\
\hline Model & $5.980 \times 10^{5}$ & 9 & 66443.37 & 8.87 & 0.0010 & significant \\
\hline A-composite & $1.806 \times 10^{5}$ & 1 & $1.806 \times 10^{5}$ & 24.12 & 0.0006 & \\
\hline B-pollutant concentration & $1.556 \times 10^{5}$ & 1 & $1.556 \times 10^{5}$ & 20.78 & 0.0010 & \\
\hline C-pH & 52747.84 & 1 & 52747.84 & 7.04 & 0.0242 & \\
\hline $\mathbf{A B}$ & 86469.64 & 1 & 86469.64 & 11.55 & 0.0068 & \\
\hline AC & 30003.33 & 1 & 30003.33 & 4.01 & 0.0732 & \\
\hline BC & 39275.64 & 1 & 39275.64 & 5.24 & 0.0450 & \\
\hline $\mathbf{A}^{2}$ & 492.85 & 1 & 492.85 & 0.0658 & 0.8027 & \\
\hline $\mathbf{B}^{2}$ & 218.91 & 1 & 218.91 & 0.0292 & 0.8677 & \\
\hline $\mathrm{C}^{2}$ & 145.86 & 1 & 145.86 & 0.0195 & 0.8918 & \\
\hline Residual & 74893.09 & 10 & 7489.31 & & & \\
\hline Lack of Fit & 74512.18 & 5 & 14902.44 & 195.62 & $<0.0001$ & significant \\
\hline Pure Error & 380.91 & 5 & 76.18 & & & \\
\hline Cor Total & $6.729 \times 10^{5}$ & 19 & & & & \\
\hline
\end{tabular}

Considering that, the F test statistic in the composite exceeds model's statistical value; it has the greatest effect on pollutant treatment. It is noteworthy that, pollutant concentration statistic was more than that of $\mathrm{pH}$, indicating that, in comparison with each other; amount of pollutant concentration had also the greatest effect on pollutant removal $[35,36]$. Moreover, mathematical model of experimental design is as Eq. (2):

$$
\begin{aligned}
\text { Removal } & =62.1933+-926.654 \times[\text { Composite }]+-1.90858 \times[\text { Pollutant concentration }] \\
(\mathrm{Cu} \mathrm{I}) & +0.39626 \times[\mathrm{pH}] 119.495 \times[\text { Composite }] \times[\text { Pollutant concentration }] \\
& +-263.959 \times[\text { Composite }] \times[\mathrm{pH}]+1.16779 \times[\text { Pollutant concentration }] \times[\mathrm{pH}] \\
& +-14242 \times[\text { Composite }]^{2}+-0.137963 \times[\text { Pollutant concentration }]^{2} \\
& +-1.68409 \times[\mathrm{pH}]^{2}
\end{aligned}
$$

\begin{tabular}{|c|c|c|c|c|c|c|}
\hline \multicolumn{7}{|c|}{ ANOVA Response Surface Methodology Quadratic Model } \\
\hline Source & Sum of Squares & df & Mean Square & F-value & p-value & \\
\hline Model & 18743.80 & 9 & 2082.64 & 28.24 & $<0.0001$ & significant \\
\hline A-composite & 930.23 & 1 & 930.23 & 12.61 & 0.0053 & \\
\hline B-pollutant concentration & 12220.74 & 1 & 12220.74 & 165.69 & $<0.0001$ & \\
\hline C-pH & 1635.10 & 1 & 1635.10 & 22.17 & 0.0008 & \\
\hline $\mathbf{A B}$ & 719.77 & 1 & 719.77 & 9.76 & 0.0108 & \\
\hline $\mathbf{A C}$ & 101.88 & 1 & 101.88 & 1.38 & 0.2671 & \\
\hline BC & 105.20 & 1 & 105.20 & 1.43 & 0.2599 & \\
\hline $\mathrm{A}^{2}$ & 11.19 & 1 & 11.19 & 0.1517 & 0.7050 & \\
\hline $\mathbf{B}^{2}$ & 12.39 & 1 & 12.39 & 0.1679 & 0.6906 & \\
\hline $\mathrm{C}^{2}$ & 25.81 & 1 & 25.81 & 0.3499 & 0.5673 & \\
\hline Residual & 737.55 & 10 & 73.75 & & & \\
\hline Lack of Fit & 683.51 & 5 & 136.70 & 12.65 & 0.0073 & significant \\
\hline Pure Error & 54.03 & 5 & 10.81 & & & \\
\hline Cor Total & 19481.35 & 19 & & & & \\
\hline
\end{tabular}

Table 4. Results obtained from ANOVA analysis regarding pollutant removal with $\mathrm{Cu}(\mathrm{II})$ 
In case of $\mathrm{Cu}(\mathrm{II})$, as $\mathrm{F}$ test statistic in pollutant concentration increased the model's value, thus it had the greatest effect on pollutant treatment. Also, $\mathrm{pH}$ statistic was more than that of composite, indicating that, in comparison with each other, amount of $\mathrm{pH}$ had the greatest effect on pollutant removal. Mathematical model of experimental design is as Eq. (3):

Removal $-59.3902+8.41095 \times[$ Composite $]+2.53439 \times[$ Pollutant concentration $]$

$(\mathrm{Cu}$ II $)+6.37589 \times[\mathrm{pH}]+10.9022 \times[$ Composite $] \times[$ Pollutant concentration $]$

$+-15.3817 \times[$ Composite $] \times[\mathrm{pH}]+0.0604375 \times[$ Pollutant concentration $] \times[\mathrm{pH}]$

$+-2146.21 \times[\text { Composite }]^{2}+-0.0328157 \times[\text { Pollutant concentration }]^{2}$

$+-0.708361 \times[\mathrm{pH}]^{2}$

Normal probability chart indicates how variables follow a normal distribution. There are still some moderate distributions even in case of normal data. Curved patterns like the "S-shape" that are only recognizable with a single look demonstrate that, better analysis will be obtained by performing a transfer function on dependent variable or model response.

According to Figure 5, distribution of normal dispersion of variables is shown linearly. Since distribution of variables is almost symmetrical, and also there is a variable located at high level of its symmetry for each variable at low level of symmetry, therefore, it can be stated that, the statistics of pollutant treatment data have a normal state. Normal state of the data indicates correct results and user accuracy.

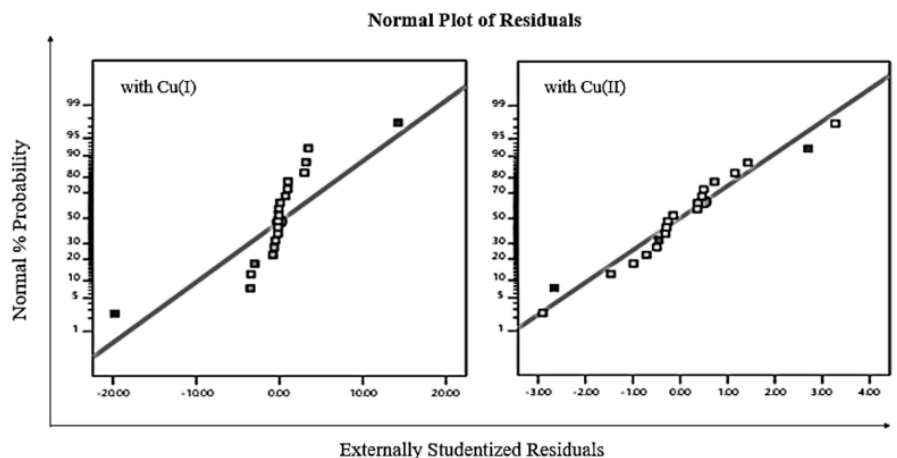

Figure 5. Distribution diagrams for normal dispersion of the variables in presence of $\mathrm{Cu}$ (I) and $\mathrm{Cu}(\mathrm{II})$.

Box -Cox is a tool used to identify the most appropriate transfer function for applying the response. The lowest point in the box indicates the best value of lambda, which is the least sum of squares remaining in transformed model. When the ratio of maximum to minimum response value is more than 3 , then there will be more ability for improving the model by the use of power function. According to Figure 6 , in which the difference between minimum and maximum is 3 , a higher potential improvement cannot be considered for the test model. 95\% confidence interval is also shown in this chart. According to Figure 6, Lambda simulates creation of a mathematical computational link between variables in current and also actual specified value. The best points for simulation and optimization of experiments were introduced as 3 and $2.46 \mathrm{for} \mathrm{Cu}$ (I) and $\mathrm{Cu}(\mathrm{II})$, respectively.

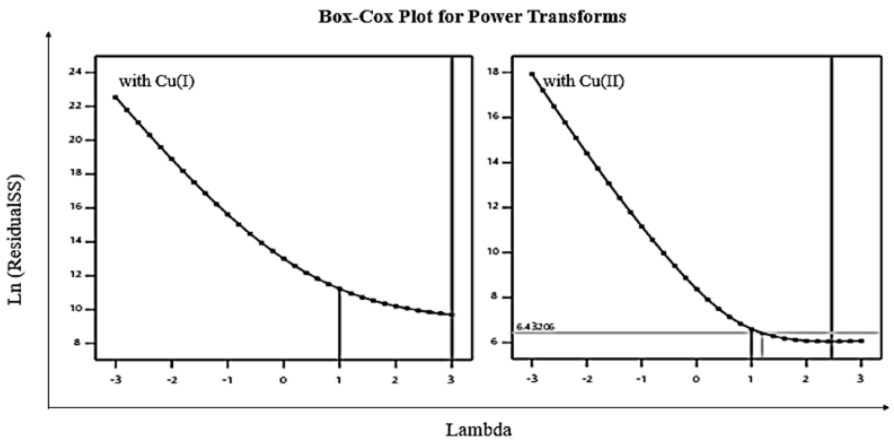

Figure 6. Box -Cox diagnostic test for pollutant removal with $\mathrm{Cu}$ (I) and $\mathrm{Cu}(\mathrm{II})$.

Regression is a statistical process for estimating the relationships between variables, upon which it can be found that whether state of relationships of the variables is at a weak, medium, or good level. In this research, according to Figure 7. related to $\mathrm{Cu}(\mathrm{II})$, it can be seen that, the relationship between independent variables and dependent variable is in good condition. Since, all responses of the experiments, which are dependent variables lie within the range of linear regression model. The better the state of relationship of the variables in a test, the more accurate the response level would be. In $\mathrm{Cu}$ (I), two dependent variables are outside normal range of statistical relationships in the graph. One of them has the lowest (negative) pollutant treatment and the other (maximum) is the limit of pollutant treatment. Since these two points are in contradiction with each other and low and high peaks of the responses, it can be said that, they are inversely proportional to each other, so the $\mathrm{Cu}(\mathrm{I})$ also has favorable conditions in relationship of the variables.

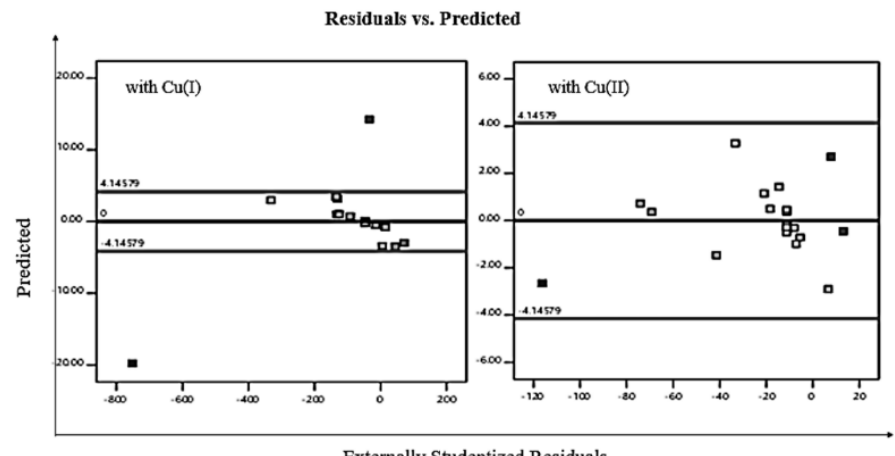

Figure 7. Comparison of regression model diagrams for prediction of current variables and current data with $\mathrm{Cu}$ (I) and $\mathrm{Cu}(\mathrm{II})$.

\subsubsection{Behavior of Variables in Pollutant Removal}

The effect of variables and their behavior in the experiment can be observed through analysis of three-dimensional diagrams obtained from the experiments.

As indicated in lowest section of the graph in Figure 8, pollutant removal results in an increase in the amount of composite, showing the relationship of this independent variable with pollutant concentration as an independent variable. By increasing amount of composite, if pollutant concentration is at its lowest level, pollutant removal has a completely negative or negative result. If the concentration value reaches 32 , maximum refinement rate occurs when the composite value is constant. This behavior shows that independent variables have the highest limit of logical relationships with each other.

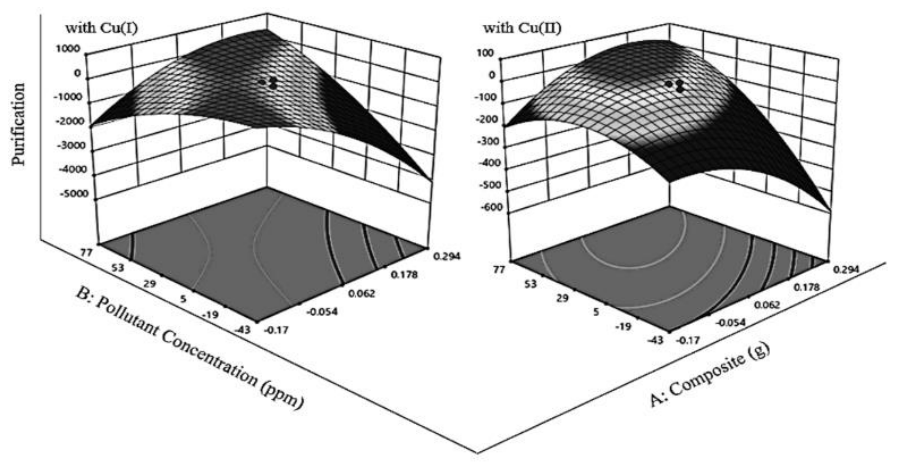

Figure 8. Three-dimensional diagram of the relationships and effects of composite and concentration changes on pollutant removal with $\mathrm{Cu}$ (I) and $\mathrm{Cu}(\mathrm{II})$. 
Figure 9. presents two diagrams with somewhat specific conditions, because they were analyzed and implemented with the least curve. In such a situation, it can be said that, independent variables have a logical and direct relationship in the RSM model.

For example, as indicated in higher section of the graphs in Figure 9, in case of an acidic environment, the composite value range at 0.062 has the highest positive effect on pollutant removal, and these trends are reasonably observable.

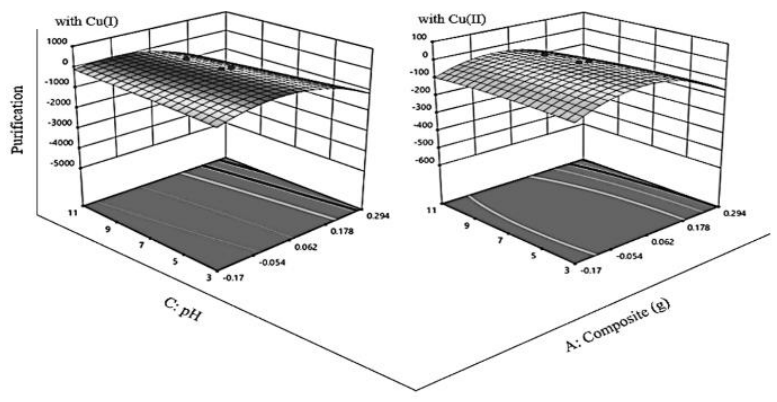

Figure 9. Three-dimensional diagram of relationships and effects of $\mathrm{pH}$ and composite on pollutant removal with $\mathrm{Cu}$ (I) and $\mathrm{Cu}(\mathrm{II})$.

Figure 10. presents behavior of two variables of $\mathrm{pH}$ and pollutant concentration. Highest pollutant removal occurred in highest part of the diagram. The more acidic the environment, the highest the rate of pollutant treatment would be even if concentration is increased.

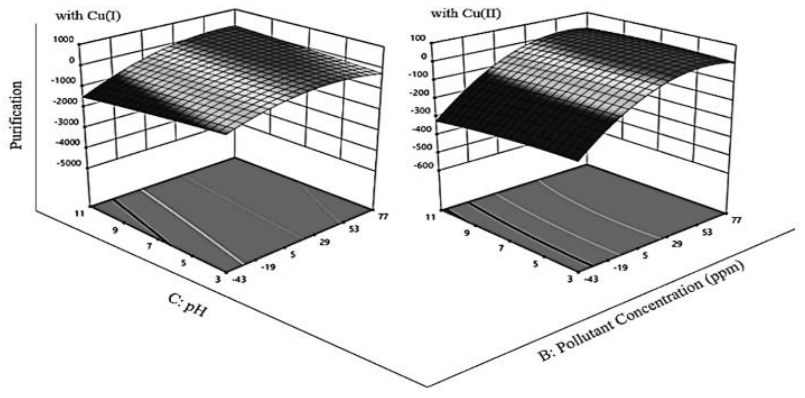

Figure 10. Three-dimensional diagram of the relationships and effects of copper and pollutant concentration on pollutant removal with $\mathrm{Cu}$ (I) and $\mathrm{Cu}$ (II).

\subsection{XRD Analysis}

Prepared MCM-41 and nanocomposites were evaluated by XRD (Rigaku, Ultima IV) technique. Measured angle ranged between $4-70^{\circ}$ with a rate of $1 \%$ min.

$\mathrm{X}$-Ray Diffraction (XRD) analysis is a suitable method used to confirm crystallinity and structure of micro and mesoporous materials. Main Miller indices of the MCM-41 are shown in Figure 11 [17, 18]. In the primary structure, Brag reflections were observed in the low area $2 \theta=5-10^{\circ}$, frequently used to identify the MCM-41 structure (Reference code: 00-049-1711).

Average crystallite size was calculated in two ways, using X'Pert HighScore Plus and OriginPro softwares. Using the first method, it was estimated based on the Debye -Scherrer Eq. (4).

$\mathrm{D}=\frac{\mathrm{k} \lambda}{\beta \cos \theta}$

Where, $\mathrm{D}$ is mean of crystalline dimension, $\mathrm{k}$ is crystal constant and is $0.89, \theta$ is Bragg angle, $\lambda$ is wavelength of $X$, and $\beta=F W H M$ (Full Width at Half Maximum).

With respect to the Debye -Scherrer model, crystallite size of detected peaks was estimated between 13.92-58.99, 8.76-96.82, and 6.15-71.56 nm for MCM41, composite with $\mathrm{Cu}(\mathrm{I})$, and composite with $\mathrm{Cu}(\mathrm{II})$, respectively [37]. The second method was the Williamson-Hall Eq. (5) [38]. In this method, unlike the Debye -Scherrer Equation that worked with the sharpest peak, 5 - 6 sharp peaks were used. In addition, to compute it, the diffraction vector (K), Eq. (6), was first calculated, where $\varepsilon$ is the strain. Mean size of the crystals, compared to particle size is given in Table 5 .

$$
\begin{aligned}
& \frac{\beta \cos \theta}{\lambda}=\frac{k}{D}+(4 \varepsilon) \times \frac{\sin \theta}{\lambda} \\
& K=\frac{2 \sin \theta}{\lambda}
\end{aligned}
$$

Although, overall structure of the MCM-41 (Reference code: 00-049-1711) did not change during synthesis and calcination process, there were also some changes. It seems that, after loading of the Copper(I)and Copper(II) salts using the linker, the products have changed into copper silicate (Reference code: 01079-0988). But, conversion rate is different. Peak intensity increased for composite with $\mathrm{Cu}$ (I) and decreased for composite with $\mathrm{Cu}$ (II) (both of them at $2 \theta=23$ ). Characteristic peak of the MCM- 41 was disappeared at $2 \theta=2.5-10^{\circ}$ in case of $\mathrm{Cu}$ (I). These results are consistent with studies by other researchers, probably due to lower thermal and chemical stability [21,39-42].

Small-angle powder X-ray diffraction pattern is also shown for MCM-41 in Figure 11. Pattern of the MCM-41 shows presence of 3 reflection peaks corresponding to planes of (100), (110), and (200), typically confirming presence of ordered hexagonal mesoporous structure of MCM-41 [42].

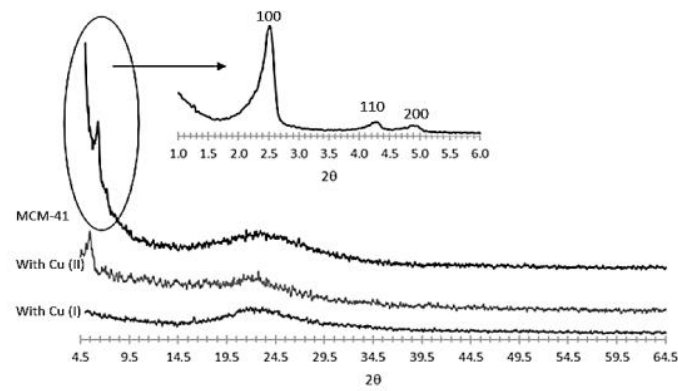

Figure 11. XRD patterns.

\subsection{FESEM, EDS, and Mapping Analysis}

Surface morphology of nanoparticle and nanocomposites was studied using FEI NOVANANOSEM 450 electron microscope. Also, elemental analysis of the nanocomposites was accomplished by an X-ray dispersive microanalyzer (Bruker, X Flash 6110).

Morphology of the samples was investigated using FESEM. Figure 15((a), (b), and (c)) shows FESEM images of MCM-41 and composites particles, respectively in two dimensions. The left side of Fig.4 (a) clearly shows that, the MCM-41 particles are agglomerated. Loading of Copper(I) and Copper(II) salts was confirmed as shown in Fig.4(b) and (c). Chemical purity of the samples was investigated by applying EDS analysis. Although the elements in the MCM-41 are silicon and oxygen, presence of some additional elements in the EDS indicates that the sample was not fully washed, and some impurities remained. Copper peaks shown in Figure 13. and Figure 14 are consistent with the XRD spectra. Distribution of different atoms on surface of crystal lattice is also shown in the form of mapping patterns beside EDSs in Figure 12, Figure 13, and Figure 14.
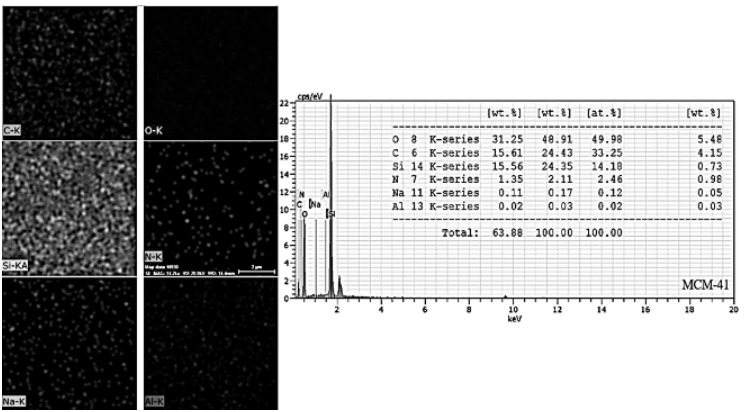

Figure 12. EDS and mapping pattern of MCM-41. 

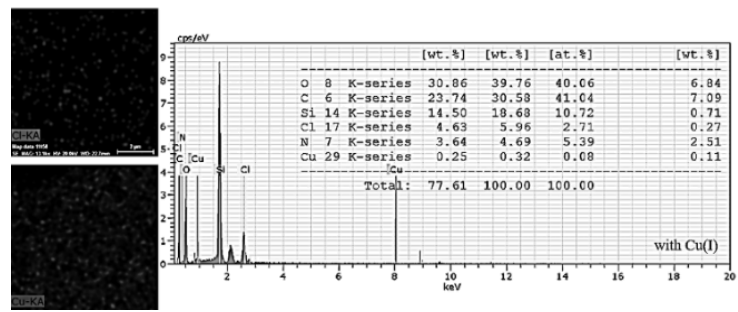

Figure 13. EDS and mapping pattern of composite with $\mathrm{Cu}(\mathrm{I})$.
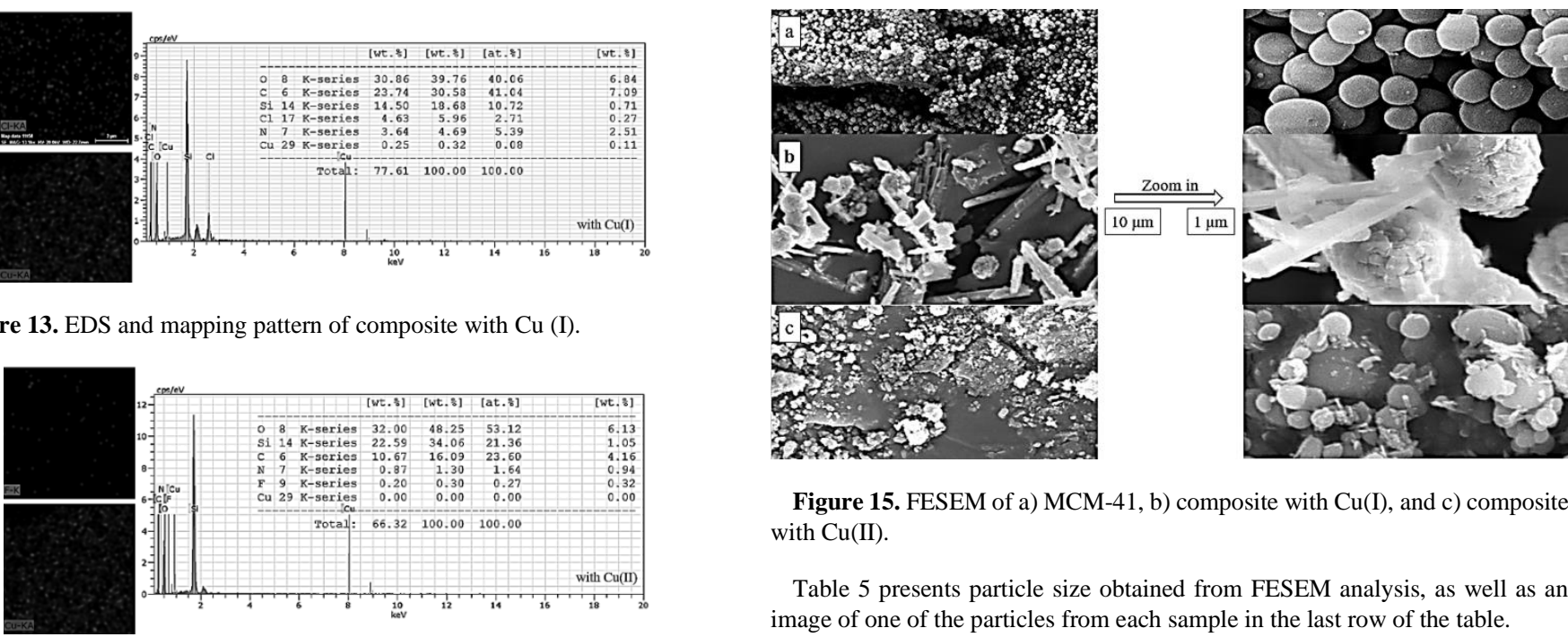

Figure 15. FESEM of a) MCM-41, b) composite with $\mathrm{Cu}(\mathrm{I})$, and c) composite with $\mathrm{Cu}(\mathrm{II})$

Table 5 presents particle size obtained from FESEM analysis, as well as an image of one of the particles from each sample in the last row of the table.

Figure 14. EDS and mapping pattern of composite with $\mathrm{Cu}(\mathrm{II})$.

Table 5. Comparison of crystallite and particle sizes of the samples.

\begin{tabular}{|c|c|c|c|c|}
\hline \multicolumn{2}{|l|}{ Sample } & MCM-41 & $\mathrm{Cu}(\mathrm{I}) / \mathrm{Van} . / \mathrm{MCM}-41$ & $\mathrm{Cu}(\mathrm{II}) / \mathrm{Van} . / \mathrm{MCM}-41$ \\
\hline \multirow{2}{*}{$\begin{array}{l}\text { Crystallite Size (nm) } \\
\text { From XRD }\end{array}$} & Scherrer Average & 27.39 & 43.18 & 31.76 \\
\hline & Williamson-Hall Size & 32.99 & 59.66 & 23.14 \\
\hline \multicolumn{2}{|c|}{$\begin{array}{l}\text { Particle Size }(\mathrm{nm}) \\
\text { From SEM (Experimental Average) }\end{array}$} & 860 & 2800 & 360 \\
\hline \multicolumn{2}{|c|}{ Strain } & 0.01293025 & 0.00241432 & -0.00040921 \\
\hline
\end{tabular}

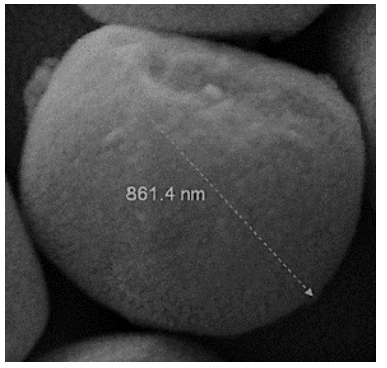

\subsection{FTIR Analysis}

Vibrational pattern of nanocomposite was determined using an FTIR spectrophotometer (Bruker, Tensor 27 and Equinox 55).

Figure 16 shows FTIR spectra to describe functional groups of raw MCM-41 and the composites. Also, presence of crystallized MCM-41 was confirmed using FTIR peaks. Table 6 presents some vibrational patterns of the samples [40, 42].

Table 6. Vibrational patterns of the samples.

\begin{tabular}{|c|c|}
\hline $\begin{array}{c}\text { Absorption band } \\
\left(\mathbf{c m}^{-1}\right)\end{array}$ & Vibration \\
\hline $\mathbf{9 6 2}$ & Si-O \\
\hline $\mathbf{1 2 3 5}$ & Asymmetric and symmetric stretching vibrations (Si-O-Si) \\
\hline $\mathbf{1 0 8 0}$ & Asymmetric and symmetric stretching vibrations (Si-O-Si) \\
\hline $\mathbf{7 9 9}$ & Asymmetric and symmetric stretching vibrations (Si-O-Si) \\
\hline $\mathbf{4 6 1}$ & Asymmetric and symmetric stretching vibrations (Si-O-Si) \\
\hline $\mathbf{1 0 2 0}$ & C-F stretching \\
\hline $\mathbf{1 1 1 3}$ & C-O stretching \\
\hline $\mathbf{1 5 1 8}$ & Vibrations of $\mathrm{N}-\mathrm{H}$ group of amines \\
\hline $\mathbf{1 5 9 8}$ & Vibrations of $\mathrm{N}-\mathrm{H}$ group of amines \\
\hline $\mathbf{2 8 3 3}$ & $\mathrm{CH}_{2}$ \\
\hline $\mathbf{2 9 4 0}$ & $\mathrm{CH}_{3}$ \\
\hline $\mathbf{3 4 7 8}$ & Stretching vibration $(\mathrm{O}-\mathrm{H})$ \\
\hline
\end{tabular}
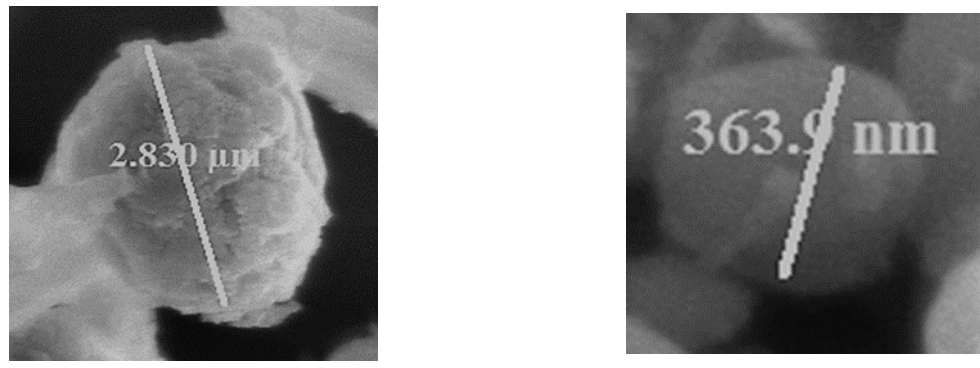

In regard to FTIR spectrum of the sample containing copper salt nanoparticles and comparing it with raw MCM-41, it can be observed that, the spectrum appeared in the core MCM-41 spectrum $\left(1086 \mathrm{~cm}^{-1}\right)$ in higher region [43, 44].

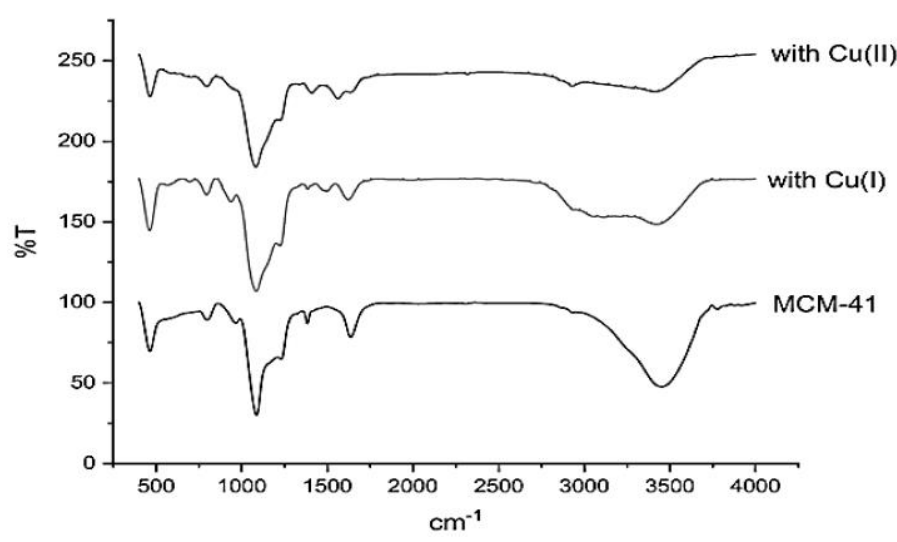

Figure 16. FTIR patterns of the materials.

\subsection{BET/BJH Analysis}

Assessment of surface area of nanoparticle and nanocomposites was performed using BET analyzer (BELSORP Mini II), and also pore size distribution was studied using $\mathrm{BJH}$ methodology with respect to nitrogen adsorption/desorption isotherm. 
As expected, results indicated that, porosities were mesoporous in the solid. According to the IUPAC, size of them was between $2-50 \mathrm{~nm}$. Table 7 summarizes the information on surface area, size, and radius of the pores.

Table 7. Summary of information presented in BET and BJH plots.

\begin{tabular}{|c|c|c|c|c|}
\hline & \multicolumn{2}{|c|}{ BET Plot } & \multicolumn{2}{c|}{$\begin{array}{c}\text { BJH Plot (Adsorption } \\
\text { Branch) }\end{array}$} \\
\cline { 2 - 5 } & $\begin{array}{c}\text { Total pore volume } \\
(\mathrm{p} / \mathrm{p} 0=0.990) \\
{\left[\mathrm{cm}^{3} / \mathrm{g}\right]}\end{array}$ & $\begin{array}{c}\text { Mean pore } \\
\text { diameter } \\
{[\mathrm{nm}]}\end{array}$ & $\begin{array}{c}\mathrm{r}_{\mathrm{p}, \text { peak }}(\text { Area }) \\
{[\mathrm{nm}]}\end{array}$ & $\mathrm{a}_{\mathrm{p}}\left[\mathrm{m}^{2} / \mathrm{g}\right]$ \\
\hline $\mathbf{M C M - 4 1}$ & 0.900200 & 3.083 & 2.435 & 1603.818 \\
\hline $\begin{array}{c}\text { Cu(I)/Van. } \\
\text { /MCM-41 }\end{array}$ & 0.1046 & 38.746 & 1.64 & 9.9793 \\
\hline $\begin{array}{c}\text { Cu(II)/Van. } \\
\text { /MCM-41 }\end{array}$ & 0.081363 & 21.508 & 1.21 & 12.7 \\
\hline
\end{tabular}

After investigating adsorption and desorption of $\mathrm{N}_{2}$ (Figure 17), it was found that, the isotherms of the diagrams are of type IV, V, and V for A, B, and C, respectively. In both types of isotherms, meso-porous type of porosity was observed. But in the isotherm IV, the interaction between adsorbent surface and the adsorbed was relatively strong. However, this interaction was weak for the isotherm V. Presence of "The Knee" (or B point) in diagram, indicates the pressure in which the monolayer is formed. In each case, route of adsorption, pale and desorption path are highlighted in bold.
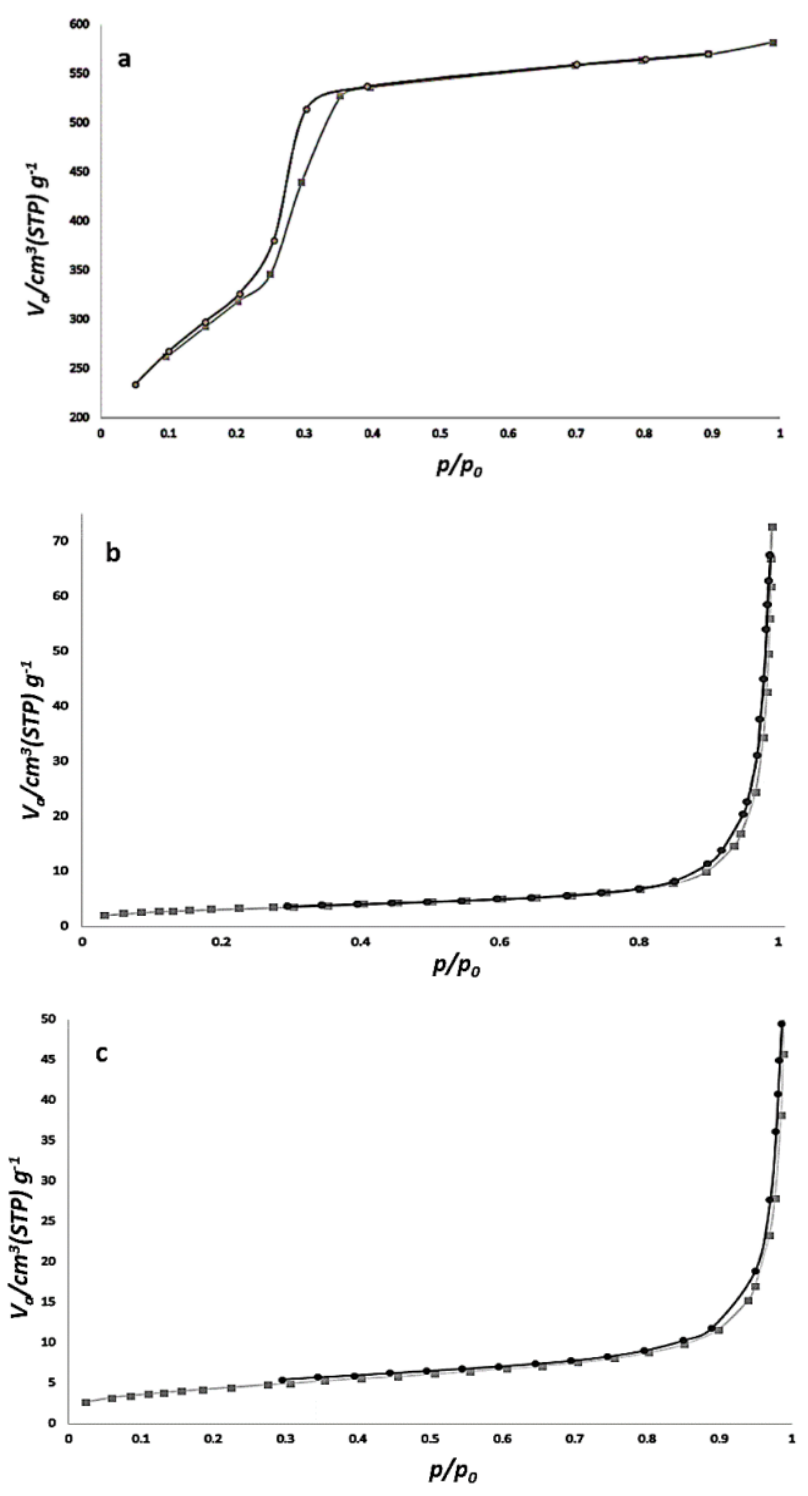

Figure 17. Adsorption/desorption isotherm of a) MCM-41, b) $\mathrm{Cu}(\mathrm{I}) / \mathrm{Van}$. /MCM-41, and c) $\mathrm{Cu}(\mathrm{II}) / \mathrm{Van}$. /MCM-41.
Also, all hysteresis rings were formed in type H1 or Type A. In Type A of hysteresis rings, the isotherms in which adsorbed or desorbed branch slopes were at average relative pressures were related to two open capillary tubes. In this capillary with a polygonal cross-section where no circular cross-section is required, the adsorbent along with absorbed sides forms a cylindrical film of fluid.

\subsection{Isotherms Calculations}

Using obtained data, all monolayer adsorption isotherms were calculated for 2 systems. Table 8 presents the best isotherms in terms of error minimization and correlation maximization.

Table 8. Isotherms, error minimization, and correlation maximization.

\begin{tabular}{|c|c|c|c|c|}
\hline Sys. & Model & Equation & $\begin{array}{c}\text { Correlation } \\
\text { Coefficient }\end{array}$ & $\begin{array}{c}\text { Error } \\
\text { Function } \\
\text { Value }\end{array}$ \\
\hline $\mathbf{C u}(\mathbf{I})$ & Frumkin & $\mathrm{C}_{\mathrm{e}}=\frac{\theta}{\mathrm{K}_{\mathrm{F}}(1-\theta)} \exp (-f \theta)$ & 1.00000 & 13.448 \\
\hline $\mathbf{C u}(\mathbf{I I})$ & $\begin{array}{l}\text { Dubinin- } \\
\text { Astakhov }\end{array}$ & $\theta_{\mathrm{DA}}=\exp \left(\frac{-\mathrm{A}_{\mathrm{D}}}{\mathrm{E}_{\mathrm{A}}}\right)^{\mathrm{n}^{\mathrm{D}}}$ & & \\
& $\mathrm{A}_{\mathrm{D}}=\mathrm{RT} \ln \left(\frac{\mathrm{C}_{\mathrm{S}}}{\mathrm{C}_{\mathrm{e}}}\right.$ & & & \\
& & & & \\
\hline
\end{tabular}

\section{CONCLUSIONS}

Optimal Amount of the Pollutant Treatments: Table 9 shows optimal versions of the test accomplished with maximum amount of pollutant treatment.

Table 9. Optimal version with $\mathrm{Cu}(\mathrm{I})$ and $\mathrm{Cu}(\mathrm{II})$

\begin{tabular}{|c|c|c|r|c|c|}
\hline Copper & composite & $\begin{array}{c}\text { pollutant } \\
\text { concentration }\end{array}$ & $\mathbf{p H}$ & purification & Desirability \\
\hline $\mathbf{C u}(\mathbf{I})$ & 0.004 & 32 & 11 & 71.255 & 0.957 \\
\hline $\mathbf{C u}(\mathbf{I I})$ & 0.041 & 31.5 & 5 & 19.405 & 1.000 \\
\hline
\end{tabular}

To oxidize and degrade the quinoline, MCM-41 nanocomposite with $\mathrm{Cu}$ (I) and $\mathrm{Cu}$ (II) active components were synthesized applying an easy method, and then it was characterized. The experiments were designed using DX software version 11 , with no auxiliary oxidant intervention.

Degradation percentages were measured by a UV spectrophotometer. After that, decomposition products were identified by the use of the GC-Mass technique. Statistical results, area of quinoline peaks, and internal standard were used to determine residual quinoline concentration. Maximum amounts of quinoline removal were about 71 and $19 \%$ corresponding to $\mathrm{Cu}$ (I) and $\mathrm{Cu}(\mathrm{II})$, respectively.

According to results of GC-MS analysis, efficiency of quinoline degradation can be explained in two ways:

1.- According to obtained information $\mathrm{d}$, the first justification is that a part of the solvent was also involved in the reaction. Then, volume decreases and initial concentration defined by the contaminant for the device also increases.

2.- Based on the results, clearly, by-products are obtained after decomposition of quinoline. This is while; some substances of quinolone remain intact. Quinoline derivatives are also found in the by-products. Absorption peak of these substances is in the same area as the quinoline absorption peak, as cited in credible scientific studies [45].

Accordingly, in calculation of reaction yield, the tester is not able to determine new pollutant concentration as well as height of absorption peaks. Thus, amount of obtained residuals is completely inaccurate and negative. 


\section{NOMENCLATURE}

Table 10. Values of parameters and Greek letters [46].

\begin{tabular}{|l|l|}
\hline $\mathbf{C}_{\mathbf{e}}$ & Equilibrium concentration of adsorbate [mg/L] \\
\hline $\mathbf{C}_{\mathbf{S}}$ & adsorbate monolayer saturation concentration $[\mathrm{mg} / \mathrm{L}]$ \\
\hline $\mathbf{D}$ & Fritz-Schlunder (IV) constant \\
\hline $\mathbf{E}_{\mathbf{A}}$ & Characteristic energy of adsorption \\
\hline $\mathbf{F}$ & interaction coefficient of the Frumkin model \\
\hline $\mathbf{K}_{\mathbf{F}}$ & Frumkin equilibrium constant \\
\hline $\mathbf{K}_{\mathbf{R}}$ & Redlich-Peterson isotherm constant [L/g] \\
\hline $\mathbf{T}$ & Absolute temperature [K] \\
\hline $\mathbf{W}$ & Mass of adsorbent [g] \\
\hline $\mathbf{n}^{\mathbf{D}}$ & Dubinin-Astakhov model exponent \\
\hline $\mathbf{q}_{\mathbf{e}}$ & The equilibrium adsorption capacity of adsorbent $[\mathrm{mg} / \mathrm{g}]$ \\
\hline $\boldsymbol{\theta}_{\mathbf{D A}}$ & Degree of micropore filling \\
\hline
\end{tabular}

\section{ACKNOWLEDGMENTS}

The authors would like to thank Dr. MASOUMEHALSADAT RAHMATI and Dr. GHAZALEH CHIZARI FARD for their assistance.

\section{COMPLIANCE WITH ETHICAL STANDARDS}

Conflict of Interest: The authors declare that there is no conflict of interest.

\section{REFERENCES}

1. JC. García-Martínez, CO. Castillo-Araiza, JA. De los Reyes Heredia, E. Trejo, A. Montesinos. Chem. Eng. 210, 53, (2012)

2. JC. García-Martínez, HG. Uribe, MM. González-Brambila, JA. Colín-Luna, YE. Escobedo-García, A. López-Gaona, L. Alvarado-Perea. Catal. Today. 305, 40, (2018)

3. P. Rayo, MS. Rana, J. Ramírez, J. Ancheyta, A. Aguilar-Elguézabal. Catal. Today. 130, 283, (2008)

4. P. Rayo, J. Ramírez, MS. Rana, J. Ancheyta, A. Aguilar-Elguézabal. Ind. Eng. Chem. Res. 48, 1242, (2008)

5. P. Schacht, L. Noreña-Franco, J. Ancheyta, S. Ramirez, I. Hernández-Pérez, LA. Garcia. Catal. Today. 98, 115, (2004)

6. IR. Guimarães, LC. Oliveira, PF. Queiroz, TC. Ramalho, M. Pereira, JD. Fabris, JD. Ardisson. APPL. CATAL. A-GEN. 347, 89, (2008)

7. PQ. Yuan, ZM. Cheng, XY. Zhang, WK. Yuan. Fuel. 85, 367, (2006)

8. MF. Dahab, YW. Lee, I. Bogardi. WATER. SCI. TECHNOL. 30, 45, (1994)

9. M. Sadeghi, S. Yekta, H. Ghaedi. APPL. SURF. SCI. 400, 471, (2017)

10. TT. Marrs, RL. Maynard, F. Sidell, editors. Chemical warfare agents: toxicology and treatment. John Wiley \& Sons Inc., 2007.

11. R. Sharma, B. Gupta, N. Singh, JR. Acharya, K. Musilek, K. Kuca, K. Kumar Ghosh. Mini-Rev. Med. 15, 58, (2015)

12. H. FOLLOWS. Technical Secretariat, Organisation for the Prohibition of Chemical Weapons, The Hague, The Netherlands, (2005)

13. A. Nezamzadeh-Ejhieh, Z. Salimi. Desalination. 280, 281, (2011)

14. J. Gao, X. Luan, J. Wang, B. Wang, K. Li, Y. Li, G. Han. Desalination. 268, $68,(2011)$

15. B. ROBABEH, SA. SHARIATI. J. CHIL. CHEM. SOC. 60, 2900, (2015)

16. A. Jukić. Natural Gas Composition, Classification, Processing, (2013)

17. R. López-Fonseca, JI. Gutiérrez-Ortiz, JL. Ayastui, MA. Gutiérrez-Ortiz, JR. González-Velasco. APPL. CATAL. B-ENVIRON. 45, 13, (2003)

18. JG. Bednorz, KA. Müller. Z. PHYS. B. CON. MAT. 64, 189, (1986)

19. AD. Berry, DK. Gaskill, RT. Holm, EJ. Cukauskas, R. Kaplan, RL. Henry. Appl. Phys. 52, 1743, (1988)

20. JM. DeSimone. Science. 297, 799, (2002)

21. A. Ghorbani-Choghamarani, F. Nikpour, F. Ghorbani, F. Havasi. RSC. Adv. 5, 33212, (2015)

22. CT. Kresge, ME. Leonowicz, WJ. Roth, JC. Vartuli, JS. Beck. Nature. 359, 710, (1992)

23. JY. Ying, CP. Mehnert, MS. Wong. Angew. Chem. Int. 38, 56, (1999)

24. M. Hajjami, F. Ghorbani, F. Bakhti. APPL. CATAL. A-GEN. 470, 303, (2014)

25. RM. Martín-Aranda, J. Čejka. TOP. CATAL. 53, 141, (2010)

26. ND. Chakkalakkal, PS. Chittilappilly, Asia. Pac. J. Res. 2320, 5504

27. II. Slowing, JL. Vivero-Escoto, CW. Wu, VSY. Lin. Adv. Drug Deliv. Rev. $60,1278,(2008)$

28. XN. Wei, HL. Wang, ZD. Li, ZQ. Huang, HP. Qi, WF. Jiang. APPL. SURF. SCI. $372,108,(2016)$
29. M. Khanmoradi, M. Nikoorazm, A. Ghorbani-Choghamarani. Appl. Organomet. 31, e3693, (2017)

30. X. Lin, X. Zeng, R. Zhou, H. Wang. REACT. KINET. MECH. CAT. 126, $353,(2019)$

31. BN. Bhadra, JY. Song, N. Uddin, NA. Khan, S. Kim, CH. Choi, SH. Jhung. APPL. CATAL. B-ENVIRON. 240, 215, (2019)

32. D. Chen, J. Shi, Y. Yao, S. Wang, C. Wu. REACT. KINET. MECH. CAT. $127,315,(2019)$

33. D. Vaddi, MV. Subbarao, MPS. Muralikrishna. Phys. Chem. Res. 7, 449, (2019)

34. M. Kamani, R. Fazaeli, M. Arjmand, M.H. Ghorbani. Phys. Chem. Res. 10.22036/pcr.2019.201520.1676 (2019)

35. A. Almasian, ME. Olya, NM. Mahmoodi, E. Zarinabadi. DESALIN WATER. TREAT. 147, 343, (2019)

36. E. Zarrinabadi, R. Abghari, A. Nazari, M. Mirjalili. Modeling and optimization of electromagnetic and saturated magnetic properties of polyester fabrics coated with $\mathrm{Ag} / \mathrm{kaolin} / \mathrm{silica}$ nanocomposites. (2018)

37. M. Brazlauskas, S. Kitrys. CHINESE. J. CATAL. 29, 25, (2008)

38. D. Nath, F. Singh, R. Das. MATER. CHEM. PHYS. 239, 122021, (2020)

39. C. Covarrubias, F. Gracia, H. Palza. APPL. CATAL. A-GEN. 384, 186, (2010)

40. NB. Castagnola, PK. Dutta. Russ. J. Phys. Chem. 102, 1696, (1998)

41. ML. Kantam, BP. Rao, BM. Choudary, KK. Rao, B. Sreedhar, Y. Iwasawa, T. Sasaki. J. MOL. CATAL. A-CHEM. 252, 76, (2006)

42. MI. Din, F. Arshad, A. Rani, A. Aihetasham, M. Mukhtar, H. Mehmood. J. Biomed. Mater. 9, 41, (2017)

43. M. Salavati-Niasari, A. Sobhani. J. MOL. CATAL. A-CHEM. 285, 58, (2008)

44. A. Nezamzadeh-Ejhieh, M. Karimi-Shamsabadi. APPL. CATAL. A-GEN. $477,83,(2014)$

45. G. Tegge.. Hirayama, K. Handbook of Ultraviolet and Visible Absorption Spectra of Organic Compounds (Handbuch der ultravioletten und sichtbaren Spektra organischer Verbin-dungen). Starch-Stärke, (1968)

46. R. Saadi, Z. Saadi, R. Fazaeli, N. ElmiFard. KOREAN. J. CHEM. ENG. 32, 787, (2015) 